\title{
Conduction disturbances after surgical correction of ventricular septal defect by the atrial approach $^{1}$
}

\author{
SUSAN M. HOBBINS, TERUO IZUKAWA, DOROTHY J. RADFORD, \\ WILLIAM G. WILLIAMS, AND GEORGE A. TRUSLER \\ From the Division of Cardiology and Cardiovascular Surgery, The Hospital for Sick Children,
Toronto, Ontario, Canada
}

SUMMARY Conduction disturbances have been documented after correction of ventricular septal defects by the ventricular route. Recently, repair of the ventricular septal defect has been through the right atrium to overcome damage to the conduction system and a right ventriculotomy.

Thirty-nine children with ventricular septal defects under the age of 5 years were operated upon by the atrial route (group 1). The incidence of conduction disturbances in this group was compared with that occurring in 19 children of comparable age with a ventricular septal defect repaired via a right ventriculotomy (group 2).

Complete right bundle-branch block developed in 13 of 39 children (33.3\%) in group 1, compared with 15 of 19 children $(78.9 \%$ ) in group 2 . This was a statistically significant reduction in complete right bundle-branch block in group 1 . The incidence of left axis deviation occurring with complete right bundle-branch block was similarly statistically reduced. Transient complete heart block and arrhythmias were not statistically different in the two groups.

The atrial approach to the repair of the ventricular septal defect significantly reduced the incidence of complete right bundle-branch block alone and occurring with left axis deviation.

Conduction disturbances after surgical correction of ventricular septal defects have been well documented (Titus et al., 1963; Kulbertus et al., 1969; Downing et al., 1972; Wolff et al., 1970; Godman et al., 1974; Okoroma et al., 1975; Subramanian, 1976; Sigmann et al., 1977). Surgical technique has been implicated. With the introduction of a new approach for the repair of ventricular septal defect via the right atrium, it was hoped to alleviate the problems caused by damage to conduction pathways. Subramanian (1976) noted that there was an incidence of postoperative complete right bundle-branch block in 44.4 per cent of patients who underwent surgery by the transatrial approach. Okoroma et al. (1975) found an incidence of 44 per cent in a similar group.

We undertook a retrospective study of 39 children who had transatrial ventricular septal

'Supported by the Ontario Heart Foundation, Ontario, Canada.

Received for publication 13 March 1978 defect repair and compared them with 19 children matched for age and sex who had a ventricular septal defect repaired via a ventriculotomy.

\section{Patients and methods}

The present series consists of 58 children with ventricular septal defects confirmed by cardiac catheterisation. They had the surgical repair at The Hospital for Sick Children, Toronto, between January 1973 and December 1976. Their ages were less than 5 years at the time of surgery.

The ventricular septal defect was an isolated lesion in 34 children. In the other 24 children associated lesions were atrial septal defect in 11 patients; persistent ductus arteriosus in 6 patients; persistent ductus arteriosus and atrial septal defect in 1 patient; persistent ductus arteriosus and coarctation of the aorta in 1 patient; infundibular pulmonary stenosis in 4 patients; and atrial septal defect and pulmonary stenosis in 1 patient.

Group 1 patients had the ventricular septal defect 
repaired through the tricuspid valve after right atriotomy. There were 39 children (20 girls; 19 boys) whose ages ranged from 2 months to 4 years and 10 months. Forty-eight patients were submitted for operation but 9 were excluded. Eight children died in the operative period and immediate postoperative electrocardiograms were not available, and 1 child was excluded because of preoperative left axis deviation on the electrocardiogram.

Group 2 patients had the ventricular septal defect repaired after a right ventriculotomy. There were 19 patients ( 9 girls; 10 boys) whose ages ranged from 8 months to 5 years. Twenty-three patients were submitted for operation but 2 children died in the operative period and were excluded as there were no immedate postoperative electrocardiograms and 2 children were excluded because of left axis deviation on the preoperative electrocardiogram.

In both groups, the majority of ventricular septal defects were of the membraneous variety, 85 per cent in group $1 ; 89.5$ per cent in group 2 . All the ventricular septal defects were closed with a patch in group 1 and 84 per cent with a patch in group 2.

The clinical records and operative records were reviewed. The maximum follow-up period was 3 years. All serial preoperative and postoperative electrocardiograms available were analysed for mean QRS axis, QRS duration, PR interval, atrial and ventricular hypertrophy, and arrhythmias. The criteria for left axis deviation were considered to be present if the mean QRS axis was lying between $240^{\circ}$ to $360^{\circ}$ which is to the left of the accepted normal for children (Moss and Emmanouilides, 1973). Complete right bundle-branch block was present when the duration of the QRS interval was $0 \cdot 10 \mathrm{~s}$ or longer (Guntheroth, 1965). We excluded any child who had electrocardiographic criteria for left axis deviation before surgery and all fatal cases as there were no postoperative electrocardiograms available.

\section{Results}

\section{GROUP 1}

Of 48 children in group 1, 8 died $(16.6 \%)$ and of 23 children in group 2, 3 died $(13.0 \%)$, thus overall mortality in the 2 groups was not statistically different. Of 14 patients in group 1 who were less than 6 months of age at operation, 6 died in the early postoperative period (Fig.). All had a low cardiac output after operation up to the time of death.

The conduction abnormalities present before and after operation in the 2 groups are compared in Table 1.

Of the 39 children who underwent surgical correction of the ventricular septal defect through

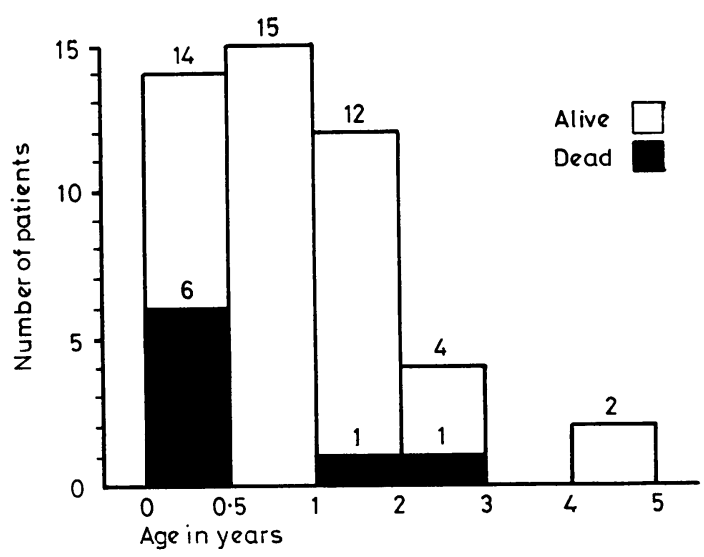

Fig. Immediate operative mortality in children with ventricular septal defect repaired through a right atriotomy (group 1). The highest mortality occurred in infants less than 6 months of age.

an atriotomy, $13(33.3 \%)$ developed immediate postoperative complete right bundle-branch block, $14(35.9 \%)$ left axis deviation, and $7(17.9 \%)$ of these patients had combined complete right bundlebranch block and left axis deviation. Eleven $(28 \cdot 2 \%)$ patients had transient complete heart block during operation. Eight $(20.5 \%)$ patients developed arrhythmias. Three children had a nodal rhythm and nodal ectopic beats immediately after operation, which were transitory. However, 2 children had atrial ectopic beats for 2 weeks and 1 month respectively, after operation. One child had atrial flutter coming off bypass and required defibrillation to convert to sinus rhythm. One child had first degree heart block and ventricular ectopic beats for 2 months after operation. One child had a wandering pacemaker.

Further analysis of our data indicated that conduction disturbances occurred more frequently in infants less than 6 months of age than in children over 6 months. These figures are compared in Table 2. Left axis deviation occurred in 75 per cent of infants less than 6 months of age, compared with 25.8 per cent in children over 6 months of age $(P<$ $0.03)$. Left axis deviation and complete right bundle-branch block occurred in 62.5 per cent of infants less than 6 months of age compared with 6.5 per cent of children over 6 months of age $(\mathrm{P}<0.005)$.

In follow-up over a maximum of 3 years of all these patients with conduction disturbances and transient arrhythmias, there have been no further electrocardiographic changes and no further complications. 
Table 1 Postoperative conduction disturbances and arrhythmias in children with ventricular septal defect

\begin{tabular}{|c|c|c|c|c|c|c|c|}
\hline Surgical approach & $\begin{array}{l}\text { No. } \\
\text { of } \\
\text { patients }\end{array}$ & $\begin{array}{l}\text { Complete right } \\
\text { bundle-branch } \\
\text { block }\end{array}$ & $\begin{array}{l}\text { Left axis } \\
\text { deviation }\end{array}$ & $\begin{array}{l}\text { Left axis } \\
\text { deviation }+ \\
\text { complete right } \\
\text { bundle-branch } \\
\text { block }\end{array}$ & $\begin{array}{l}\text { Transient } \\
\text { complete heart } \\
\text { block }\end{array}$ & $\begin{array}{l}\text { Left axis devia- } \\
\text { tion, complete } \\
\text { right bundle- } \\
\text { branch block, and } \\
\text { complete heart } \\
\text { block }\end{array}$ & $\begin{array}{l}\text { Arrhythmias } \\
\text { d }\end{array}$ \\
\hline Transatrial & 39 & $13(33 \cdot 3 \%)$ & $14(35.9 \%)$ & $7(17 \cdot 9 \%)$ & $11(28 \cdot 2 \%)$ & $2(5 \cdot 1 \%)$ & $8(20 \cdot 5 \%)$ \\
\hline Transventricular & 19 & $15(78.9 \%)$ & $9(47 \cdot 3 \%)$ & $8(42 \cdot 1 \%)$ & $5(26 \cdot 3 \%)$ & $3(15 \cdot 8 \%)$ & $6(31.5 \%)$ \\
\hline
\end{tabular}

Table 2 Postoperative conduction disturbances and arrhythmias after repair of ventricular septal defect through the right atrium

\begin{tabular}{|c|c|c|c|c|c|c|c|}
\hline Age & $\begin{array}{l}\text { No. } \\
\text { of } \\
\text { patients }\end{array}$ & $\begin{array}{l}\text { Complete right } \\
\text { bundle-branch } \\
\text { block }\end{array}$ & $\begin{array}{l}\text { Left axis } \\
\text { deviation }\end{array}$ & $\begin{array}{l}\text { Left axis } \\
\text { deviation }+ \\
\text { complete right } \\
\text { bundle-branch } \\
\text { block }\end{array}$ & $\begin{array}{l}\text { Transient } \\
\text { complete heart } \\
\text { block }\end{array}$ & $\begin{array}{l}\text { Left axis devia- } \\
\text { tion, complete } \\
\text { right bundle- } \\
\text { branch block, } \\
\text { and complete } \\
\text { heart block }\end{array}$ & Arrhythmias \\
\hline$<6$ months & 8 & $5(62.5 \%)$ & $6(75 \%)$ & $5(62.5 \%)$ & $2(25 \%)$ & $1(12.5 \%)$ & $4(50 \%)$ \\
\hline$>6$ months & 31 & $8(25 \cdot 8 \%)$ & $8(25.8 \%)$ & $2(6.5 \%)$ & $10(32 \cdot 2 \%)$ & $1(3 \cdot 2 \%)$ & $4(12.9 \%)$ \\
\hline
\end{tabular}

GROUP 2

Fifteen $(78.9 \%$ ) children developed postoperative complete right bundle-branch block and $9(47.3 \%)$ had left axis deviation. Combined complete right bundle-branch block and left axis deviation was present in $8(42.1 \%)$ patients. Five $(26.3 \%)$ children developed transient complete heart block during operation. One child had varying complete heart block for 4 days after operation. Six children $(31.5 \%)$ developed arrhythmias. Four patients developed a junctional rhythm, 3 children had a transient arrhythmia, but 1 child developed the arrhythmia 1 year after operation. One child required a pacemaker for 10 days after operation, and went on to develop premature ventricular contractions, sinus arrest, and nodal escape beats in the 2 years after operation and required the implantation of a demand pacemaker at that time. Yet another patient who had no disturbances during operation developed ventricular ectopics for the first 6 months after operation, before returning to a normal rhythm.

Two children died in the early postoperative period of low cardiac output syndrome. One child died at home, but we have no further details.

\section{Discussion}

Pulmonary artery banding has been a standard life saving procedure for infants with large ventricular septal defects in whom vigorous medical treatment has failed to control symptoms. However, subsequent debanding and surgical repair of the defect may be difficult. Combined mortality for banding and subsequent total repair may be as high as 51 per cent (Kirklin et al., 1976). Thus, single stage corrective surgery is attractive if morbidity and mortality are low.

Our initial experience with transatrial repair shows a mortality of 43 per cent in infants under 6 months of age and 3.6 per cent in children between 6 months and 2 years of age. There were 6 out of 14 patients in this subsection but only 1 had a complex lesion. If this patient is removed from our numbers, the mortality for less than 6 months of age for uncomplicated ventricular septal defect repair via an atriotomy is 35 per cent. Kirklin et al. (1976) reviewed published reports in which there was a similarly high mortality (33\%) for this age group. There was no correlation between weight, surface area, preoperative symptoms, and duration of operation to account for this mortality figure. Another study from this hospital (Rowe and Trusler, 1977) confirms a mortality of 20 per cent in infants less than 1 year of age repaired via an atriotomy. Comparison of results of various surgical approaches is important to determine optimal repair. Conduction disturbances are a major consideration.

Ventricular septal defect repair via an atriotomy was first performed in our hospital in 1973. Thus, the maximum follow-up period for this group is 
only 3 years. Surgical correction through a right ventriculotomy has been carried out in selected patients since 1955. The presence of other associated cardiac abnormalities has influenced the decision of the approach and this fact is important in analysing our results.

Complete right bundle-branch block has been found to occur in 60 to 100 per cent (Kulbertus et al., 1969; Gelband et al., 1971; Okoroma et al., 1975; Subramanian, 1976) of cases of ventricular septal defect repaired via a ventriculotomy. When a right atrial approach is used there is an incidence of 0 to 44.4 per cent (Gelband et al., 1971; Okoroma et al., 1975; Subramanian, 1976) of complete right bundle-branch block. Similarly, our results show a significantly reduced incidence of complete right bundle-branch block with an atriotomy of 33.3 per cent, compared with 78.9 per cent with a ventriculotomy $(P<0.001)$. The incidence of left axis deviation occurring with complete right bundlebranch block was also statistically significantly reduced $(P<0.05)$.

The mechanisms of production of complete right bundle-branch block electrocardiographic pattern with operation has been discussed extensively. Gelband et al. (1971) have implicated the incision through the ventricular muscle causing damage to the peripheral branches of the right bundle-branch. Coggin et al. (1960) and Massing and James (1972) share this view. Kaiser et al. (1970) have described an approach at the time of operation using an electrode probe to localise the specialised AV conduction pathways. This mapping technique requires a beating heart and is not adaptable to the child in whom circulation and cardiac arrest is required.

An alternative explanation which is applicable in at least a proportion of cases is direct injury to the main right bundle in its course over the edge of the membraneous ventricular septal defect. It is intimately related with the posteroinferior portion of such defects (Kirlin et al., 1957; Lev, 1959, 1960; Titus et al., 1963). This fairly constant relation of the bundle to the margin of the orifice seems to explain the high frequency of injury after surgical repair of the defect (Kulbertus et al., 1969). The lesions have been shown to be due to suturing, manipulation, and hypoxia (Thung et al., 1962), localised haemorrhage, traumatic disruption by suture, inflammation, or infarction (Titus et al., 1963; Lev et al., 1964).

Similarly, direct trauma explains injury to the right bundle and anterior branch of the left main bundle, producing electrocardiographic findings of complete right bundle-branch block and left axis deviation. Izukawa et al. (1971) and Godman et al. (1974) found that patients with this combination of injuries with a history of transient complete heart block in the immediate postoperative period were at risk for the development of late postoperative complete heart block. In our limited follow-up period of group 1 patients with this pattern, none developed late complete heart block or sudden death. There was 1 late sudden death in group 2, the full details of which are not known.

Our results show a reduced incidence of complete right bundle-branch block and left axis deviation with complete right bundle-branch block when the ventricular septal defect is repaired via a right atriotomy. The high incidence of complete right bundle-branch block after repair of the ventricular septal defect through a right ventriculotomy is probably the result of peripheral injury to the right bundle. The development of complete right bundle-branch block with left axis deviation after a ventricular septal defect repair through the atrium must be considered central in origin. The introduction of ventricular septal defect repair through the right atrium has statistically reduced the incidence of bifascicular block.

Acknowledgements to $\mathrm{Mr} \mathrm{D}$. Cook, statistician.

\section{References}

Coggin, C. J., Wareham, E. E., and Selvester, R. H. (1960). Postventriculotomy right bundle-branch block: its aetiology (abstract). Circulation, 22, 734.

Downing, J. W., Jr., Kaplan, S., and Bove, K. B. (1972). Postsurgical left anterior hemiblock and right bundle-branch block. British Heart Fournal, 34, 263-270.

Gelband, H., Waldo, A. L., Kaiser, G. A., Bowman, F. O., Jr., Malm, J. R., and Hoffman, B. F. (1971). Etiology of right bundle branch block in patients undergoing total correction of tetralogy of Fallot. Circulation, 44, 1022-1033.

Godman, M. J., Roberts, N. K., and Izukawa, T. (1974). Late postoperative conduction disturbances after repair of ventricular septal defect and tetralogy of Fallot. Circulation, 49, 214-221.

Guntheroth, W. G. (1965). Pediatric Electrocardiography. W. B. Saunders, Philadelphia.

Izukawa, T., Clarke, M., and Trusler, G. A. (1971). Late complete trifascicular heart block resulting from cardiac surgery (abstract). Circulation, 43 and 44, Suppl. II, 181.

Kaiser, G. A., Walso, A. L., Beach, P. A., Bowman, F. O., Jr., Hoffman, B. F., and Malm, J. R. (1970). Specialized cardiac conduction system. Improved electrophysiologic identification technique at surgery. Archives of Surgery, 101, 673-676.

Kirklin, J. W., Appelbaum, A., and Bargeron, L. M., Jr. (1976). Primary repair versus banding for ventricular septal defects in infants. In The Child with Congenital Heart Disease After Surgery, pp. 3-9, ed B. S. Langford Kidd and R. D. Rowe. Futura Publishing Company, Mount Kisco, N.Y.

Kirklin, J. W., Harshbarger, H. G., Donald, D. E., and Edwards, J. E. (1957). Surgical correction of ventricular septal defect: anatomic and technical considerations. Fournal of Thoracic Surgery, 33, 45-59.

Kulbertus, H. E., Coyne, J. J., and Hallidie-Smith, K. A. (1969). Conduction disturbances before and after surgical 
closure of ventricular septal defect. American Heart fournal, 77, 123-131.

Lev, M. (1959). The architecture of the conduction system in congenital heart disease. Il. Tetralogy of Fallot. Archives of Pathology, 67, 572-587.

Lev, M. (1960). The architecture of the conduction system in congenital heart disease. III. Ventricular septal defect. Archives of Pathology, 70, 529-549.

Lev, M., Fell, E. H., Arcilla, R., and Weinberg, M. H. (1964). Surgical injury to the conduction system in ventricular septal defect. American fournal of Cardiology, 14, 464-476.

Massing, G. K., and James, T. N. (1972). Conduction and block in the right bundle branch block. Circulation, 45, 1-3.

Moss, A. J., and Emmanouilides, G. C. (1973). Practical Pediatric Electrocardiography, pp. 28-31. J. B. Lippincott, Philadelphia and Toronto.

Okoroma, E. O., Guller, B., Maloney, J. D., and Weidman, W. H. (1975). Etiology of right bundle branch block pattern after surgical closure of ventricular septal defects. American Heart fournal, 90, 14-18.

Rowe, R. D., and Trusler, G. A. (1977). Ventricular septal defect: prospects for operated and non-operated infants during the first year of life. Coeur, 8, 301-308.

Sigmann, J. M., Perry, B. L., Behrendt, D. M., Stern, A. M., Kirsh, M. M., and Sloan, H. E. (1977). Ventricular septal defect: results after repair in infancy. American fournal of Cardiology, 39, 66-71.

Subramanian, S. (1976). Ventricular septal defect: problems in repair in infancy. In The Child with Congenital Heart Disease After Surgery, pp. 11-24, ed B. S. Langford Kidd and R. D. Rowe. Futura Publishing Company, Mount Kisco, N.Y.

Thung, N., Dammann, J. F., Jr., Diaz-Perez, R., Thompson, W., Jr., Sanmarco, M., and Mehegan, C. (1962). Hypoxia as a cause of hemorrhage into the cardiac conduction system, arrhythmia and sudden death. Fournal of Thoracic and Cardiovascular Surgery, 44, 687-698.

Titus, J. L., Daugherty, G. W., Kirklin, J. W., and Edwards, J. E. (1963). Lesions of the atrioventricular conduction system after repair of ventricular septal defect: relation to heart block. Circulation, 28, 82-88.

Wolff, G. S., Rowland, T. W., and Ellison, R. C. (1970). Surgically induced right bundle branch block with left anterior hemiblock: an ominous sign in postoperative tetralogy of Fallot. Circulation, 46, 587-594.

Requests for reprints to Dr T. Izukawa, Department of Cardiology, The Hospital for Sick Children, 555 University Avenue, Toronto, Ontario, Canada. M5G 1 X8. 